\title{
Factors Affecting the Readiness of Medical Doctors and Patients with Chronic Conditions toward the Usage of Smartphones in the Saudi Arabian Healthcare Sector
}

\author{
http://dx.doi.org/10.3991/ijim.v9i1.4279 \\ B.M. Al-Mahadeen \\ Tafila Technical University, Tafila, Jordan
}

\begin{abstract}
Numerous studies have reported the rapid increase in the number of individuals who use smartphones. However, smartphones appear to be increasingly used by healthcare workers, particularly physicians and nurses. Therefore, this study aims to investigate the readiness of medical doctors and patients with chronic conditions in using and adopting smartphones for communication. This study employs the Technology Acceptance Model to examine the behavior of people in using smartphones from the perspectives of trust and rural areas. To realize our objective, we conducted a questionnaire survey that involved medical doctors and patients with chronic conditions. Our particular focus was Al Qunfudhah City in Saudi Arabia. More than 200 questionnaires were distributed to people belonging to different healthcare sectors in the rural areas of Al Qunfudhah City. Our aim was to include every possible scenario and to obtain excellent perspectives. The results that we eventually analyzed indicated that trust factor and rural areas significantly influence the readiness of people belonging to the healthcare sector toward using smartphones. The results of our study concur with the findings of other studies. Our results indicate that smartphones and other high-technology gadgets are now necessary and accepted devices in the different healthcare fields. However, further studies should explore the challenges and effects of smartphone use in the healthcare sector.
\end{abstract}

Index Terms-Healthcare, Individual Factors, Rural Area, Saudi Arabia, Smartphone, TAM.

\section{INTRODUCTION}

Many organizations have accepted using mobile technology devices, such as personal digital assistants (PDAs), mobile phones, and smartphones, in the course of their operation and the work of their employees. The advanced features of these mobile devices have enticed various organizations to require the use of such devices for the communication needs of their employees. In particular, smartphones showcase innovative technology that has combined the features and capabilities of PDAs and mobile phones. As a result, smartphones have significantly influenced the method of communications that organizations implement.

Based on an IDC study [1], about one billion of smartphones have been shipped to hundreds of countries in 2013 . This figure was $38.4 \%$ higher than that in 2012 .
The increase in smartphone sales is a reflection of the growing popularity of smartphones and other mobile devices in our everyday affairs. Moreover, such popularity is an indication that smartphones are now indispensable in the daily activities of an individual. This development has prompted the current researchers to thoroughly investigate the drive of individuals to use smartphones for communicating important or serious matters, instead of engaging in personal or face-to-face conversations. Examples of these conversations are those related to medical discussions and consultations.

The most widely used model in determining user acceptance of new technology usage is Technology Acceptance Model (TAM). [2][3] Conducted studies related to mobile technology that utilized numerous theories, including TAM, in understanding the rationale of people in using mobile devices (i.e., smartphones) at work. Although the aforementioned studies have explored the use of smartphones in various organizations, including those involved in healthcare, only a limited number of studies have evaluated the insights of people in using smartphones in their work.

[4] explained that a few studies have cited an increase in the use of PDAs in the healthcare sector. The researchers added that such increase has influenced the outlook of both healthcare workers and patients. The dynamic advancements in information technology (IT) have resulted in the publication of numerous empirical studies on the use of PDAs. However, the technology behind this device either has become stagnant or became obsolete [5]. Studies on the use of smartphones based on the insights of people into using the latest technology have presented new methods of embracing technology itself and circumventing the problems concerning delays.

This study aims to investigate and clarify the drive of medical doctors and patients in Saudi Arabia that influences smartphone use as a means of communication. This study will utilize TAM as a theoretical model to thoroughly clarify the factors that influence people, particularly those in the healthcare sector, to use smartphones. The intention of and attitude of people toward the use of smartphones are assumed to be influenced when they use such devices without any difficulty and when they have trust in using the latest technology without any apprehension regarding limited information. Moreover, this study assumes that the nature of rural areas and the distance 
from medical centers encourage patients, especially the elderly, to use smartphones as a means of communication with medical doctors. Finally, this study offers a model to aid researchers in understanding the relationship between trust and ease of use. This relationship influences the behavior of people in the healthcare sector in using smartphones and suggests directions for future research in this area.

\section{BACKGROUND OF THE STUDY}

\section{A. Healthcare and Smartphone use}

Mobile communication has a massive potential to introduce significant changes in medical and healthcare interventions in society. Several previous studies have assessed the use of mobile phones in supporting interventions in the healthcare and public health sectors, particularly in healthcare research data collection and collation [6], as well as in supporting medical and healthcare education and clinical practice in society [7]. The success of mobile phone usage in supporting telemedicine and remote healthcare in developing countries has been highlighted by several studies [8]. Examples of such use include off-site medical diagnosis [9] and as information support for the treatment of HIV cases in far-flung rural areas [10].

Recent literature has featured studies that evaluate the particular functionalities of smartphones, including an assessment of the use of on-board digital diaries in symptom research [11], short message service (SMS) usage in behavior change management [12], in sexual health education [13], and in improving the adherence of patients to antiretroviral treatment [14]. A comparison of mobile phone records usage against conventional paper-based records in controlled drug trials has been performed by one study [15].

Numerous application opportunities are offered in GPSand location-enabled smartphones, which can further assist the independent living of persons with disabilities or those with multiple chronic conditions [16, 17], as well as in epidemiology/public health survey and community data collection [18].

[19] reported the existence of more than 7,000 documented cases of smartphone health apps. [20,21] revealed that the use of mobile phones and handheld computing devices in health and clinical practices has been extensively reviewed. [20] emphasized several important features that render the superiority of mobile phones to other information and communication technologies. Such advantages include portability, continuous uninterrupted data stream, and immense capability resulting from sufficient computing power that support multimedia software applications. Areas where mobile communication is utilized have reported considerable economic benefits, particularly telemedicine and sectors that provide remote healthcare advice [22].

\section{B. Healthcare and Smartphone use}

TAM is an extension of reasoned action theory [23]. Fig. 1, shows that TAM determines the informal interactions among the system design, perceived usefulness, perceived ease of use, attitude toward use, behavioral intention to use, and actual usage behavior. TAM favorably reflects the factors by which design choices influence

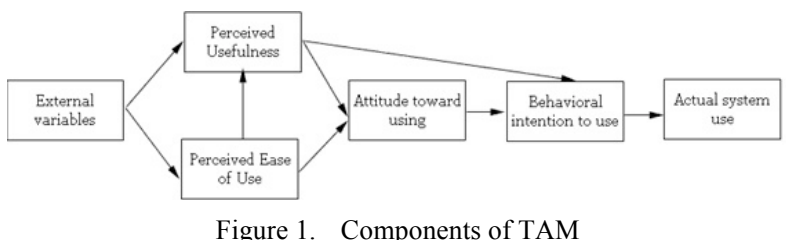

user acceptance, and needs to be valuable in the situations positioned for forecasting and evaluating user acceptance of IT [24-26].

\section{Literature review and research hypotheses}

[27] assessed the acceptance of medical doctors of telemedicine technology. They suggested that TAM may be more appropriate than other theories that examine technology acceptance by individual professionals. Moreover, they argued that the integrated model may lack significant additional explanatory power. In the wireless PDA context, [28] suggested that the intention of the user to perform general tasks is influenced by perceived usefulness (PU) and perceived ease of use (PEOU) Perceived playfulness affects the intention of the user to play games, whereas PU influences user intention to transact. Moreover, studies posited that the acceptance of a wireless Internet environment via mobile technologies is affected by wireless trust environment, PU, PEOU, system complexity, and social influences affect [29-31]. Mobile services can be available at any time and any place within the broad context of smartphone acceptance. Thus, the definition of PU is the degree of consumer belief that mobile services can be integrated into their daily activities [32].

The relationship between stakeholders considers trust as a critical component [33-38], because it is the characteristic that provides the fundamental value to medical relationships. However, trust is likewise critical in a more instrumental manner, as well as crucial to the willingness of patients to seek care, disclose confidential information, submit to treatment, and follow the recommendations of medical doctors [36]. Trust issues are similarly core to current discussions on healthcare delivery structure and regulation. Moreover, trust measures have been proposed as a valuable new tool for monitoring the performance of individual providers and health plans [36]. Consequently, the current study gauges the effects of trust on the attitude and intention of healthcare sector members, including medical doctors and patients, in using smartphones.

This study likewise considers the influence of rural areas on smartphone use. Saudi Arabia has extensive rural areas that are scattered and distant from each other. This characteristic adversely affects the quality of medical services. This study was conducted in the coastal city AlQunfudhah in southern Saudi Arabia and approximately $380 \mathrm{~km}$ south of Mecca. The population of this city is roughly 300,000. Numerous rural areas in Al-Qunfudhah are far from center of the city. For instance, all of the city residents are served only by one sugar center. Patients with chronic conditions who require medical consultations or periodic visits to the doctor must travel more than 100 $\mathrm{km}$ simply to avail of medical services. Such conditions in these areas present opportunities for productive areas of study. [39] argued that rural areas affect the behavior of individuals in using smartphones to accomplish specific tasks, including medical appointments and consultations. The current study assumes that rural areas have significant and positive effects on smartphone use in the Saudi Arabi- 
an healthcare sector. Fig. 2, shows the factors derived from TAM, including trust and rural area factors, as well as the hypotheses tested in the current study.

For smartphone services, PEOU can be described as the issue of navigational easiness on the device and availability of personalized elements. PEOU would have a positive effect on attitude toward smartphones. Moreover, trust between stakeholders and in using smartphones affect the attitude toward using smartphone in the healthcare sector; trust is expected to have a positive effect on attitude. Of the last connection between user attitude and intention to use in the model, the attitude of users toward smartphones is expected to have a positive effect on the intention to use smartphones. The list of the hypotheses considered in this study is shown in Table 1.

\section{Methodology}

A structured survey method is employed in this study, with the review of prior studies serving as the basis for the survey questionnaire developed. People who work in the healthcare sector and patients with chronic conditions are the subject units of the survey analysis. After developing the survey questions, the survey was initially tested by conducting semi-structured interviews with healthcare sector members. Several specialists in questionnaire development were also interviewed to ensure content validity. Suggestions and feedback were solicited from the interviewees to improve survey clarity. The suggestions and feedback were used as the basis for refining the survey questions.

In November 2013, the newly revised survey version was used for conducting a pilot study. Thirty-three completed survey questionnaires were collected. Unsatisfied measurement items were dropped after the measurement models were statistically tested. Moreover, a review of the responses was conducted to identify additional problems that may come up with the questionnaire. After the pilot study, the final survey version was distributed to patients with chronic conditions in different far-flung rural areas, as well as to the medical staff members in various centers in Saudi Arabia, particularly in Al-Qunfudhah. Only 128 survey questionnaires from the total of 145 collected were used for data analysis.

\section{A. Measurement}

This study adopted all of the measurement indicators from prior literature. The behavioral intention to use was adopted from [40], the attitude toward use was adopted from [40, 41], PEOU was adopted from [42, 43], and the trust questions were adopted from [44].

\section{DATA ANALYSIS}

\section{A. Measurement models}

Partial least squares (PLS) technique of structural equation modelling (SEM) was employed in the current study to examine both measurement and structural models for two reasons. First, PLS is capable of specifying both the relationships among constructs in the research model, and the measurement of constructs in the research model [45]. Compared with LISREL or AMOS, PLS does not have to posit any strict assumption regarding population, scale measurement, or distribution [46]. Second, PLS is less restrictive on the sample size with unbiased estimates [47]

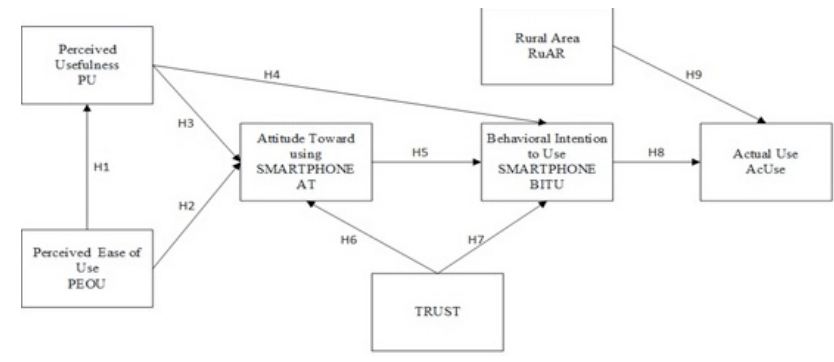

Figure 2. Proposed Research Model

TABLE I.

LIST OF HYPOTHESES

\begin{tabular}{|c|c|}
\hline $\begin{array}{l}\text { Hypothesis } \\
\text { Number }\end{array}$ & Description \\
\hline H1 & $\begin{array}{l}\text { Perceived ease of use directly affects perceived useful- } \\
\text { ness. }\end{array}$ \\
\hline $\mathrm{H} 2$ & $\begin{array}{l}\text { Perceived ease of use positively affects the attitude } \\
\text { toward smartphone use. }\end{array}$ \\
\hline H3 & $\begin{array}{l}\text { Perceived usefulness has a significant positive relation- } \\
\text { ship with the attitude of patients toward smartphone use. }\end{array}$ \\
\hline $\mathrm{H} 4$ & $\begin{array}{l}\text { Perceived usefulness positively influences patient inten- } \\
\text { tion to use a smartphone. }\end{array}$ \\
\hline H5 & $\begin{array}{l}\text { Attitude toward smartphone use has a significant posi- } \\
\text { tive relationship with the behavioral intention to use a } \\
\text { smartphone. }\end{array}$ \\
\hline H6 & $\begin{array}{l}\text { High level of trust for using smartphones in the } \\
\text { healthcare sector positively influences patient attitude } \\
\text { toward smartphone use. }\end{array}$ \\
\hline $\mathrm{H} 7$ & $\begin{array}{l}\text { High level of trust for using smartphones in the } \\
\text { healthcare sector positively influences patient intention } \\
\text { to use a smartphone. }\end{array}$ \\
\hline H8 & $\begin{array}{l}\text { Behavioral intention to use a smartphone has a positive } \\
\text { relationship on the actual use of a smartphone. }\end{array}$ \\
\hline H9 & $\begin{array}{l}\text { Rural areas have a strong and positive relationship with } \\
\text { the actual use of smartphones. }\end{array}$ \\
\hline
\end{tabular}

TABLE II.

RELIABILITIES AND VALIDITY

\begin{tabular}{|c|c|c|c|c|}
\hline & $\begin{array}{c}\text { Number } \\
\text { of items }\end{array}$ & AVE & $\begin{array}{c}\text { Composite } \\
\text { Reliability (CR) }\end{array}$ & Cronbach's $\alpha$ \\
\hline AT & 6 & 0.6945 & 0.9313 & 0.9106 \\
\hline AcUse & 2 & 0.838 & 0.9118 & 0.809 \\
\hline PEOU & 4 & 0.6844 & 0.8964 & 0.8458 \\
\hline PITU & 5 & 0.696 & 0.9193 & 0.8893 \\
\hline PU & 4 & 0.5419 & 0.8244 & 0.7246 \\
\hline RuAr & 3 & 0.6812 & 0.8632 & 0.8043 \\
\hline TRUST & 5 & 0.7574 & 0.9397 & 0.9198 \\
\hline
\end{tabular}

We conducted a $t$-test by following the procedure of [48] to evaluate non-response bias.

PLS bootstrap re-sampling procedure was performed to examine the stability of estimates [49] and to develop robust confidence intervals [50] in both measurement and structural models. To assess reliability, the factor loadings of indicators on latent constructs must be higher than 0.7 so that strong reliability can be established. Cronbach's $\propto$ was similarly used to assess reliability. The acceptable score for Cronbach's $\propto$ is 0.7 for the existing constructs. All of the measurement items in Table II are higher than 0.7 , which indicate adequate reliabilities. 
Table III shows that all of the loadings of 29 standardized indicators were higher than the ideal cut-off level of 0.7 [50, 51]. One item exhibited a loading of 0.6956 , which is approximately equal to the recommended level of 0.70 ; thus, this item was retained in the model. Consequently, the loading values indicate that the reliabilities of measurement items are acceptable.

The composite reliabilities (CRs) should be higher than the threshold value of 0.7 to ensure construct level validity; thus, suggesting good internal consistency [52, 53]. All of the CRs of the constructs used in the measurement models range from 0.8244 (PU) to 0.9397 (Trust). This result indicates that the current research model ensures construct level reliability. Moreover, the average variance extracted (AVE), which represents the proportion of the average variance between constructs and indicator variables, must be higher than 0.5 to imply good convergent validity [49]. All of the CRs and AVE indicate good convergent validity, as shown in Table II.

AVE and inter-construct correlation were compared to evaluate the discriminant validity of each variable. Based on the suggestion of [51], the square root of AVE should be greater than the correlations of variables to prove discriminant validity. Every construct had a larger square root of AVE than its correlations with other constructs, indicating that the values of diagonal elements are greater than those of off-diagonal elements. This result demonstrates that our measurement items have discriminant validity $[49,51,52]$. The values shown in Table IV indicate good discriminant validity.

\section{RESUlTS}

Hypothesis 1 is supported by the results, which confirmed the existence of a direct effect between ease of use and usefulness, with path coefficient $=0.210$ and $t$-value $=$ 4.786 at $p<0.01$. Moreover, the attitude of patients toward smartphone use in the healthcare sector is significantly and positively affected by PEOU, with path coefficient $=0.524$ and $t$-value $=11.24$. This result likewise indicates that Hypothesis 2 is supported by this study. These results imply the importance of considering smartphone application designs to be easy to use by different user levels. This consideration could enhance the willingness of patients to use smartphones as a means of communication with medical doctors.

Our data results do not support Hypothesis 3. Based on the results, no significant relationship exists between perceived usefulness and the attitude of patients toward smartphone use in the healthcare sector, with path coefficient $=0.043$ and $t$-value $=0.894$. By contrast, Hypothesis 4 is supported by the results of this study, indicating that perceived usefulness has a significant effect on the behavioral intention of patients to use smartphones.

Our data results support Hypothesis 5. Our research model determined the statistical positive relationship between attitude toward smartphone use and behavioral intention to use a smartphone, with path coefficient = 0.246 and $t$-value $=5.054$ at $\mathrm{p}<0.01$ level. Based on these results, the attitude of users toward smartphone use contributes to an increasing behavioral intention to use smartphones.
TABLE III.

CROSS-LOADINGS FOR MEASUREMENT INDICATORS

\begin{tabular}{|c|c|c|c|c|c|c|c|}
\hline & AT & AcUse & PEOU & PITU & PU & RuAr & TRUST \\
\hline AT1 & 0.8438 & 0.0354 & 0.5671 & 0.4125 & 0.1021 & -0.1909 & 0.4521 \\
\hline AT2 & 0.8643 & -0.0641 & 0.5142 & 0.4594 & 0.0902 & -0.2757 & 0.4307 \\
\hline AT3 & 0.8807 & 0.0812 & 0.5279 & 0.3589 & 0.1833 & -0.1172 & 0.3786 \\
\hline AT4 & 0.8987 & 0.0414 & 0.5373 & 0.4707 & 0.1135 & -0.1018 & 0.4093 \\
\hline AT5 & 0.8005 & 0.0284 & 0.4911 & 0.2744 & 0.0871 & -0.1086 & 0.3732 \\
\hline AT6 & 0.6956 & 0.0499 & 0.4104 & 0.3259 & 0.1727 & -0.0089 & 0.3376 \\
\hline AcUse3 & 0.0064 & 0.8957 & 0.0161 & 0.0174 & 0.2839 & 0.3524 & -0.1326 \\
\hline AcUse4 & 0.0454 & 0.9348 & 0.0106 & 0.0848 & 0.3576 & 0.4244 & 0.0273 \\
\hline PEOU2 & 0.5273 & 0.0178 & 0.8261 & 0.4941 & 0.3041 & -0.0359 & 0.4502 \\
\hline PEOU3 & 0.5317 & -0.0038 & 0.8562 & 0.5438 & 0.1501 & -0.103 & 0.4726 \\
\hline PEOU4 & 0.5467 & 0.0757 & 0.8635 & 0.5375 & 0.199 & -0.1365 & 0.5169 \\
\hline PEOU5 & 0.4964 & -0.056 & 0.7591 & 0.6333 & 0.0086 & -0.2241 & 0.4837 \\
\hline PITU1 & 0.3463 & 0.0326 & 0.6055 & 0.7341 & 0.1371 & -0.1484 & 0.4133 \\
\hline PITU2 & 0.4353 & 0.1305 & 0.5705 & 0.8779 & 0.1079 & -0.1165 & 0.4511 \\
\hline PITU3 & 0.3724 & 0.0422 & 0.5421 & 0.8871 & 0.1358 & -0.1051 & 0.4407 \\
\hline PITU4 & 0.4151 & -0.0488 & 0.5293 & 0.814 & 0.1712 & -0.1265 & 0.4179 \\
\hline PITU5 & 0.3786 & 0.0835 & 0.5153 & 0.8491 & 0.1379 & -0.0674 & 0.4912 \\
\hline PU1 & 0.0088 & 0.1726 & 0.143 & 0.1461 & 0.6716 & 0.1402 & -0.149 \\
\hline PU3 & 0.0336 & 0.3647 & 0.1614 & 0.1439 & 0.7005 & 0.1487 & -0.0234 \\
\hline PU4 & 0.1328 & 0.2809 & 0.0634 & 0.0388 & 0.7198 & 0.1854 & -0.0031 \\
\hline PU5 & 0.2096 & 0.2485 & 0.2025 & 0.1323 & 0.8412 & -0.0553 & 0.0339 \\
\hline RuAr2 & -0.226 & 0.0494 & -0.1606 & -0.2123 & -0.2116 & 0.7394 & -0.1674 \\
\hline RuAr3 & -0.1398 & 0.4899 & -0.1073 & -0.0729 & 0.0939 & 0.9653 & -0.0948 \\
\hline RuAr4 & -0.1636 & 0.1968 & -0.1751 & -0.2124 & 0.1563 & 0.7517 & -0.174 \\
\hline TRUST2 & 0.4538 & 0.0183 & 0.4884 & 0.4091 & 0.0448 & -0.0262 & 0.8247 \\
\hline TRUST3 & 0.3336 & 0.0063 & 0.5254 & 0.4553 & -0.0463 & -0.0915 & 0.8793 \\
\hline TRUST4 & 0.4824 & -0.0812 & 0.5051 & 0.5349 & -0.0096 & -0.1789 & 0.9011 \\
\hline TRUST5 & 0.4131 & -0.092 & 0.5088 & 0.5124 & -0.0562 & -0.1339 & 0.9046 \\
\hline TRUST6 & 0.3841 & -0.0442 & 0.5002 & 0.3813 & -0.0956 & -0.1483 & 0.8387 \\
\hline
\end{tabular}

TABLE IV.

DISCRIMINANT VALIDITY

\begin{tabular}{|c|c|c|c|c|c|c|c|}
\hline & AT & AcUse & PEOU & BITU & PU & RuAr & TRUST \\
\hline AT & $\mathbf{0 . 8 3 3 3 7 0}$ & & & & & & \\
\hline AcUse & 0.030628 & $\mathbf{0 . 9 1 5 4 3 9}$ & & & & & \\
\hline PEOU & 0.635475 & 0.014229 & $\mathbf{0 . 8 2 7 2 7 7}$ & & & & \\
\hline BITU & 0.467931 & 0.0598 & 0.660889 & $\mathbf{0 . 8 3 4 2 9 1}$ & & & \\
\hline PU & 0.146456 & 0.354133 & 0.210111 & 0.164875 & $\mathbf{0 . 7 3 6 1 2 2}$ & & \\
\hline RuAr & -0.170099 & 0.427742 & -0.144409 & -0.13384 & 0.100876 & $\mathbf{0 . 8 2 5 3 7 7}$ & \\
\hline TRUST & 0.479129 & -0.04761 & 0.57967 & 0.532146 & -0.03503 & -0.13535 & $\mathbf{0 . 8 7 0 2 8}$ \\
\hline
\end{tabular}

PEOU, Perceived Ease of Use; AT, Attitude toward using Smartphone; BITU, Behavioural Intention to Use Smartphone; AcUse, Actual Use; PU, Perceived Usefulness; RuAr, Rural Area

The numbers in pink cells are the square root of AVE. For adequate discriminant validity, the number in parentheses should be greater than the corresponding off-diagonal elements. 
Our results support Hypotheses 6 and 7, confirming the positive relationship between trust and attitude toward smartphone use, with path coefficient $=0.177$ and $t$-value $=4.179$ at $\mathrm{p}<0.01$ significance level. Moreover, the behavioral intention of patients to use smartphones is significantly affected by trust, with path coefficient $=0.419$ and $t$-value $=9.120$ at $\mathrm{p}<0.01$. These results suggest that individual readiness to use smartphones will be enhanced by maintaining trust between users when they use this device through the extension of the area of use and the provision of trusted applications that offer a means of communication between individuals.

Our results similarly support Hypotheses 8 and 9. The current research model determines the statistical positive relationship between behavioral intention to use and actual use of smartphones, with path coefficient $=0.119$ and $t$ value $=2.628$ at $p<0.01$. Moreover, a significant positive relationship exists between rural areas and actual use of smartphones, with path coefficient $=0.444$ and $t$-value $=$ 15.105 at $p<0.01$. These results indicate the importance of focusing on identifying and developing specialized applications for the healthcare sector, and providing patients with a means of communication with medical doctors. Fig. 3, shows the detailed research model results.

\section{CONCLUSION}

A conceptual model for adopting smartphones in the healthcare sector based on TAM was proposed in this study. This model was recommended to evaluate the effects of trust, rural area, and all TAM factors on the adoption and use of smartphones in various healthcare sectors. All stakeholders have been considered in this study. These stakeholders include members of the healthcare sector, particularly medical workers, and the citizens who live in far-flung areas away from medical centers. The results indicated that the readiness of patients and medical doctors to use and adopt smartphones is related to several factors, namely, trust, ease of use, and perceived usefulness. Moreover, the rural areas positively influence the actual use of smartphones among the healthcare sector members. This study is expected to aid the developers of smartphone applications in considering features that encourage people to adopt smartphones in various work sectors, especially in the healthcare sector. The effects of other factors on smartphone use in the healthcare sector should likewise be assessed in future studies. These factors include infrastructure availability, privacy, time, demographic factors, national culture, and organizational culture.

\section{REFERENCES}

[1] IDC, International Data Corporation https://www.idc.com/getdoc. jsp?containerId=prUS24645514, Accessed: 16 April 2014.

[2] J.H. Cheong, and M. Park, "Mobile internet acceptance in Korea", Internet Research, vol. 15, no. 2, pp. 125-40, 2005. http://dx.doi.org/10.1108/10662240510590324

[3] E. Mao, M. Srite, J.B. Thatcher, and O. Yaprak, "A research model for mobile phone service behaviors: empirical validation in the US and Turkey", Journal of Global Information Technology Management, vol. 8, no. 4, pp. 7-27, 2005. http://dx.doi.org/10.1080/1097198X.2005.10856406

[4] A.E. Carroll, and D.A. Christakis, "Pediatricians' use of and attitudes about personal digital assistants", Pediatrics, vol. 113, no. 2, pp. 238-42, 2004. http://dx.doi.org/10.1542/peds.113.2.238

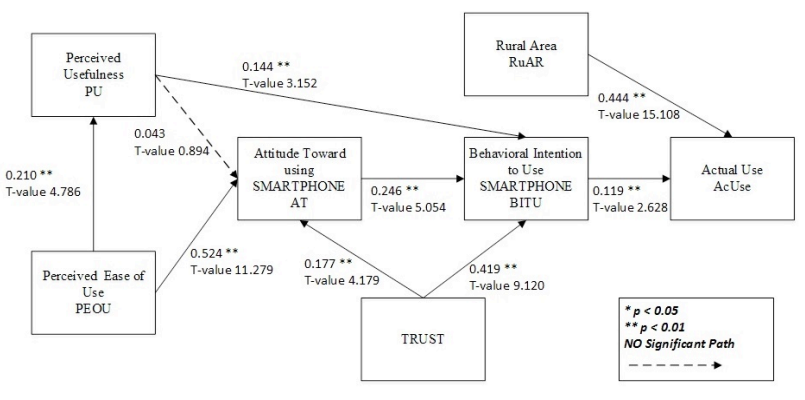

Figure 3. Research Results

[5] I. Benbasat, and B.W. Zmud, "Empirical research in information systems: the practice of relevance", MIS Quarterly, vol. 23, no. 1, pp. 3-16, 1999. http://dx.doi.org/10.2307/249403

[6] J.A. Blaya, H.S. Fraser, and B. Holt, E-health technologies show promise in developing countries. Health Affairs, 29:244-251, 2010. http://dx.doi.org/10.1377/hlthaff.2009.0894

[7] AM. Lindquist, PE. Johansson, GI. Petersson, B-I. Saveman, GC. Nilsson, The use of the Personal Digital Assistant (PDA) among personnel and students in health care: a review. Journal of Medical Internet Research, 10:e31, 2008. http://dx.doi.org/10.2196/ jmir. 1038

[8] W. Kaplan, Can the ubiquitous power of mobile phones be used to improve health outcomes in developing countries? Global Health, 2:9, 2006. http://dx.doi.org/10.1186/1744-8603-2-9

[9] AW. Martinez, ST. Phillips, E. Carillho, SW. Thomas, H. Sindi, GM, Whitesides Simple Telemedicine for Developing Regions: Camera Phones and Paper-Based Microfluidic Devices for RealTime, Off Site Diagnosis. Analytical Chemistry, 80:3699-3707. 2008. http://dx.doi.org/10.1021/ac800112r

[10] HSF. Fraser, D. Jazayeri, P. Nevil, Y. Karacaoglu, PE. Farmer, E. Lyon, Smith Fawzi MKC, F. Leandre, SS. Choi, and KS. Mukherjee, An information system and medical record to support HIV treatment in rural Haiti, BMJ, 329(7475):1142-1146, 2004. http://dx.doi.org/10.1136/bmj.329.7475.1142

[11] C. Burton, D. Weller, and M. Sharpe, Are electronic diaries useful for symptoms research? A systematic review. Journal of Psychosomatic Research, 62:553-561, 2007. http://dx.doi.org/10.1016/ j.jpsychores.2006.12.022

[12] BS. Fjeldsoe, AL. Marshall, and YD. Miller, Behavior change interventions delivered by mobile telephone short-message service, American Journal of Preventive Medicine, 36(2):165-173, 2009. http://dx.doi.org/10.1016/j.amepre.2008.09.040

[13] MS. Lim, JS. Hocking, ME. Hellard, CK. Aitken: SMS STI, A review of the uses of mobile phone text messaging in sexual health. International Journal of STD \& AIDS, 19:287-290, 2008. http://dx.doi.org/10.1258/ijsa.2007.007264

[14] C. Pop-Eleches, H. Thirumurthy, JP. Habyarimana, JG. Zivin, MP. Goldstein, D. de Walque, L. Mackeen, J. Haberer, S. Kimaiyo, J. Sidle, D. Ngare, DR. Bangsberg, Mobile phone technologies improve adherence to antiretroviral treatment in a resource-limited setting: a randomized controlled trial of text message reminders, AIDS 2011. http://dx.doi.org/10.1097/QAD.0b013e32834380c1

[15] SJ. Lane, NM. Heddle, E. Arnold, I. Walker, A review of randomized controlled trials comparing the effectiveness of hand held computers with paper methods for data collection, BMC Medical Informatics and Decision Making, 6:23, 2006. http://dx.doi.org/10.1186/1472-6947-6-23

[16] J. Coughlan, R. Manduchi, A Mobile Phone Wayfinding System for Visually Impaired Users, Assist technol Res Ser, 25(2009):849, 2009.

[17] MN. Kamel Boulos, A. Anastasiou, E. Bekiaris, M. Panou, Geoenabled technologies for independent living: examples from four European projects, Technology and Disability, 23(1):7-17, 2011.

[18] DM. Aanensen, DM. Huntley, EJ. Feil, F. al-Own, and BG. Spratt: EpiCollect, Linking smartphones to web applications for epidemiology, ecology and community data collection. PLoS One, 4(9):e6968, 2009. http://dx.doi.org/10.1371/journal.pone.0006968

[19] A. Kailas, CC. Chong, F. Watanabe, From mobile phones to personal wellness dashboards, IEEE Pulse, 7/8: 57-63, 2010. http://dx.doi.org/10.1109/MPUL.2010.937244 
[20] C. Free, G. Phillips, L. Felix, L. Galli, V. Patel, and P. Edwards, The effectiveness of $\mathrm{M}$ health technologies for improving health and health services: a systematic review protocol, BMC Research Notes, 3:250. http://dx.doi.org/10.1186/1756-0500-3-250

[21] M. Terry, Medical apps for smartphones, Telemed J E Health, 16(1):17-22, 2010. http://dx.doi.org/10.1089/tmj.2010.9999

[22] HC. Noel, DC. Vogel, JJ. Erdos, D. Cornwall, F. Levin, Home telehealth reduces healthcare costs. Telemed J E Health, 10(2):170-183, 2004. http://dx.doi.org/10.1089/tmj.2004.10.170

[23] J. Blythe, Consumer Behaviour. London: Thomson Learning, 2008.

[24] V. Venkatesh, and F.D Davis, "A Theoretical Extension of the Technology Acceptance Model: Four Longitudinal Field Studies". Management Science, 46 (2), pp. 186-204, 2000. http://dx.doi.org/10.1287/mnsc.46.2.186.11926

[25] F. D. Davis, R. P Bagozzi,., and P. R. Warshaw, User acceptance of computer technology: a comparison of two theoretical models, Management science, 35(8), 982-1003, 1989 http://dx.doi.org/ $10.1287 / \mathrm{mnsc} .35 .8 .982$

[26] F. D. Davis, Perceived usefulness, perceived ease of use, and user acceptance of information technology, MIS Quarterly, 13(3), 319340, 1989. http://dx.doi.org/10.2307/249008

[27] P. Chua, and P.J. Hu, "Information technology acceptance by individual professionals: a model comparison approach," Decision Sciences, vol. 32, no. 4, pp. 699-720, 2001. http://dx.doi.org/10.1111/j.1540-5915.2001.tb00978.x

[28] X. Fang, S. Chan, J. Brzeinski, and S. Xu, "Moderating effects of task type on wireless technology acceptance", Journal of Management Information Systems, vol. 22, no. 3, pp. 123-57, 2005. http://dx.doi.org/10.2753/MIS0742-1222220305

[29] Y. Lu, J.K. Lee, A. Sears, J.A. Jacko, and K. Charters, "Why don't physicians use their personal digital assistants?", paper presented at the AMIA 2003 Symposium Proceedings, pp. 405-9, 2003.

[30] I. Constantiou, J. Damsgaard, and L. Knutsen, "Exploring perceptions and use of mobile services: user differences in an advancing market", International Journal of Mobile Communications, vol. 4, no. 3, 2006.

[31] Koivumaki, T., Ristola, A. and Kesti, M. (2006), "Predicting consumer acceptance in mobile services: empirical evidence from an experimental end user environment", International Journal of Mobile Communications, Vol. 4 No. 4. http://dx.doi.org/10.1504/ IJMC.2006.008950

[32] M. Kleijen, M. Wetzels, and K. Ruyter, "Consumer acceptance of wireless finance", Journal of Financial Services Marketing, Vol. 8 No. 3, pp. 206-11, 2004. http://dx.doi.org/10.1057/palgrave. fsm. 4770120

[33] AC. Kao, DC. Green, NA. Davis, JP. Koplan, and PD. Cleary, Patients' trust in their physicians: effects of choice, continuity, and payment method. J Gen Intern Med;13:681-6, 1998. http://dx.doi.org/10.1046/j.1525-1497.1998.00204.x

[34] SD. Pearson, LH. Raeke, Patients' trust in physicians: many theories, few measures, and little data, J Gen Intern Med;15:50913, 2000. http://dx.doi.org/10.1046/j.1525-1497.2000.11002.x

[35] DH. Thom, B. Campbell, Patient-physician trust: an exploratory study, J Fam Pract; 44:169-76, 1997.

[36] MA. Hall, E, Dugan, B. Zheng, AK. Mishra, Trust in physicians and medical institutions: what is it, can it be measured, and does it matter? Milbank Q; 79:613-39, 2001. http://dx.doi.org/10.1111/ 1468-0009.00223

[37] VB. Sheppard, RE. Zambrana, AS. O'Malley, Providing health care to low-income women: a matter of trust. Fam Pract; 21:484 91, 2004. http://dx.doi.org/10.1093/fampra/cmh503

[38] AG 3rd. Mainous, N. Kerse, CD. Brock, K. Hughes, C. Pruitt, Doctors developing patient trust: perspectives from the United States and New Zealand. NZFP;30:336-40, 2003.

[39] S. Kulkarni, P. Agrawal, Smartphone driven healthcare system for rural communities in developing countries. In Proceedings of the 2nd International Workshop on Systems and Networking Support for Health Care and Assisted Living Environments (p. 8). ACM, June, 2008. http://dx.doi.org/10.1145/1515747.1515758

[40] G.W. Bock, R.W. Zmud, and Y. G. Kim, Behavioral intention formation in knowledge sharing: examining the roles of extrinsic motivators, social-psychology forces, and organizational climate. MIS Quarterly, 29(1), 87-111, 2005.

[41] M.G. Morris, V. Venkatesh, and P.L Ackerman, Gender and age differences in employee decisions about new technology: an extension of the theory of planned behavior. Engineering Management, 52(1), 69-84. doi: 10.1109/TEM.2004.839967, 2005. http://dx.doi.org/10.1109/TEM.2004.839967

[42] C. Cobanoglu, An Analysis of Blogs as a Teaching Tool as Perceived by Hospitality Management Students. Journal of Hospitality, Leisure, Sport and Tourism Education, 5, 2, 83-88, 2006. http://dx.doi.org/10.3794/johlste.52.138

[43] Z. Selamat, N. Jaffar, and H.B. Ong, Technology Acceptance in Malaysian Banking Industry. European Journal of Economics, Finance and Administrative Sciences, vol. 17, 143-155, 2009.

[44] I. K Lai, V. W Tong and D. C. Lai, Trust factors influencing the adoption of internet-based interorganizational systems. Electronic Commerce Research and Applications, 10(1), 85-93, 2011. http://dx.doi.org/10.1016/j.elerap.2010.07.001

[45] H. Wold, Introduction to the second generation of multivariate analysis. New York, NY: Paragon House, 1989.

[46] M. Haenlein, A. M. Kaplan, A beginner's guide to partial least squares analysis, 2004.

[47] R. F. Falk, and N. B. Miller, A primer for soft modeling, Akron, OH: University of Akron Press. (1992).

[48] S. J. Armstrong and T. S. Overton, Estimating non-response bias in mail surveys. Journal of Marketing Research, 14, 396-402, 1977. http://dx.doi.org/10.2307/3150783

[49] W. Chin, B. Marcolin, and P. Newsted, A partial least squares latent variable modeling approach for measuring interaction effects: Results from a Monte Carlo simulation Study and an Electronic-Mail Emotion/Adoption Study. Information Systems Research, 14, 189-217, 2003. $\quad$ http://dx.doi.org/10.1287/ isre.14.2.189.16018

[50] W. W. Chin, The partial least squares approach for structural equation modeling. Lawrence Erlbaum Associates, 1998.

[51] D. Barclay, C. Higgins, and R. Thompson, The partial least squares (PLS) approach to causal modeling: Personal computer adoption and use as an illustration. Technology Studies, 2, 285324, 1995.

[52] C. Fornell, and D. F. Larker, Evaluating structural equation models with unobservable variables and measurement error, Journal of Marketing Research, 18, 39-50, 1981. http://dx.doi.org/10.2307/ $\underline{3151312}$

[53] J. Hulland, Use of partial least squares (PLS) in strategic management research: A review of four recent studies, Strategic Management Journal, 20, 195-204, 1999. http://dx.doi.org/10.1002/ (SICI)1097-0266(199902)20:2<195::AID-SMJ13>3.0.CO;2-7

\section{AUTHORS}

B. M. Mahadeen is with the Computer Department, Tafila Technical University, Tafila, Jordan. He is the Associate Professor of CIS. He received his BSc in Computer Science in 1991 from Mutah University, Karak, Jordan. He obtained his MSc in Computer Science from Al-Bayt University, Mafraq, Jordan, in 1999. In 2005, he received his $\mathrm{PhD}$ in Computer Information Technology from the Arab Academy, Amman Jordan. His research interests are in wireless sensor networks, interconnection networks, RFID applications, and healthcare information systems. (e-mail:dr.bmahadeen@gmail.com). 